\title{
Onomatopeias: análise de conteúdo nas histórias em quadrinhos Recrutinha'
}

\author{
Karenine Miracelly Rocha da Cunha \\ Nídia Ledur Müller de Castro ${ }^{3}$ \\ Roberto de Castro ${ }^{4}$
}

\begin{abstract}
Resumo
O presente discute o emprego das onomatopeias nas histórias em quadrinhos da revista Recrutinha. O estude reúne vinte e sete edições das HQ analisadas, de 2008 a 2017, tendo como método empregado a análise de conteúdo de Bardin. A discussão trata da atratividade estética e de conteúdo de uma revista do Exército Brasileiro voltado à comunicação organizacional entre a instituição e o público-alvo, crianças e adolescentes. Conclui-se que o recurso onomatopeia é de vital importância para a dinâmica da narrativa quadrinística pela criação de uma dinâmica sonora e de movimento.
\end{abstract}

Palavras-chave: Onomatopeia; Histórias em Quadrinhos; Recrutinha.

\begin{abstract}
This paper discusses the use of onomatopoeia in Recrutinha magazine comics. The study gathers twenty-seven editions of the analyzed comics, from 2008 to 2017, using Bardin's content analysis as a method. The discussion deals with the aesthetic attractiveness and content of a magazine of the Brazilian Army focused on organizational communication between the institution and the target audience, children and adolescents. It is concluded that the onomatopoeic resource is of vital importance for the dynamics of the quantum narrative by the creation of a dynamic sound and movement.
\end{abstract}

Keywords: Onomatopoeia; Comics; Recrutinha.

\section{Introdução}

As onomatopeias são palavras que reproduzem som ou ruído, e nas histórias em quadrinhos - HQ adquirem maior significação e expressão. É o rompimento da mudez gráfica para a compreensão imaginária acústica do enredo (RABAÇA; BARBOSA, 2001).

\footnotetext{
1 Parte da pesquisa de Mestrado em Comunicação Social.

2 Doutora em Ciências da Comunicação pela Universidade de São Paulo.

kareninemrc@hotmail.com

3 Bacharel em Direito. nidiamuller@hotmail.com

4 Mestre em Desenvolvimento Rural pela Universidade de Cruz Alta. Mestrando em

Comunicação Social pelo Centro de Estudos de Pessoal. rdecastrol4@hotmail.com
} 


\section{VOZES $_{\text {\&DÁLORO }}^{\mid}$}

Itajaí, v. 17, n. 02, jul./dez. 2018

O autor Humberto Eco foi um dos grandes expoentes do uso das onomatopeias. Em 1969, em um trabalho com amostras de 39 revistas de Eco, foram encontradas 173 variedades diferentes de onomatopeias. No Brasil, as edições das HQ Pererê de Ziraldo chegaram a 149 diferentes onomatopeias (CIRNE, 1971; RAMOS, 2016).

A leitura dos quadrinhos para Ramos (2016) requer a percepção das cenas narrativas, a interação das imagens nas bordas, a ação das personagens e a relação das falas, o tempo e o espaço onde ocorre a história. Nessa perspectiva é fundamental o uso das onomatopeias para dar a ação à trama em HQ.

O estudo apresenta as HQ da revista organizacional do Exército Brasileiro, Recrutinha, que tem a função de servir ao relacionamento de crianças e adolescentes com o Exército Brasileiro. O objetivo do estudo é aprofundar a discussão sobre o emprego de onomatopeias e realizar uma crítica pela perspectiva da análise de conteúdo.

O escopo do trabalho apresenta pesquisa quantitativa e qualitativa de onomatopeias, bem como a discussão da importância do recurso para a cognição e comunicação da mensagem. Os resultados permitirão um diagnóstico da utilização das onomatopeias nas HQ Recrutinha.

\section{Materiais e métodos}

O estudo é uma pesquisa descritiva que utiliza o instrumento da análise de conteúdo, conforme Bardin (2011) pelo registro ou recorrência de palavra, no caso as onomatopeias. A pesquisa quali-quantitativa foi realizada numa amostra de 27 edições da revista Recrutinha, publicadas entre os anos de 2008 e 2017, disponíveis no site do Exército Brasileiro, (RECRUTINHA, 2008-2017), e entrevista semi-estruturada (DUARTE; BARROS, 2017), com o autor das HQ Recrutinha, o desenhista Luiz Fernando Vieira Moreira Rocha. Estes métodos permitem a discussão da relevância do recurso onomatopeias no conteúdo das HQ organizacionais.

\section{Resultados e discussões}

As onomatopeias, para Luyten (1984), são a grande beleza sonora das HQ, identificando a reprodução de sons e ruídos fornecendo às HQ uma trilha sonora com equivalência de significação ao recurso cinematográfico. Muitas das onomatopeias foram incorporadas às HQ brasileiras da cultura quadrinística norte-americana.

Nas HQ, as onomatopeias são códigos que auxiliam na transmissão de ideias. Para Meireles (2015), linguagens precisam transmitir conteúdos, mostrar emoções e reações para dar continuidade à trama. As onomatopeias possuem aspecto analógico (letras) e 


\section{VOZES $_{\text {\&DÁLORO }}^{\mid}$}

Itajaí, v. 17, n. 02, jul./dez. 2018

linguístico (qualidade sonora atribuída à representação). No quadro, a imagem e a palavra se complementam permitindo um sentido denotativo e interpretativo em prol do significado.

A Tabela 1 revela o levantamento quantitativo das onomatopeias no período estudado.

Tabela 1 - Uso de onomatopeias nas histórias em quadrinhos da revista Recrutinha

\begin{tabular}{lll}
\hline Ano & Edições & Onomatopeias \\
\hline 2008 & 4 & - \\
2009 & 3 & 4 \\
2010 & 3 & 13 \\
2011 & 1 & 4 \\
2012 & 2 & 6 \\
2013 & 3 & 5 \\
2014 & 3 & 10 \\
2015 & 3 & 20 \\
2016 & 3 & 14 \\
2017 & 2 & 11 \\
Total & 27 & 87 \\
\hline
\end{tabular}

Fonte: o autor com base em (RECRUTINHA, 2008-2017).

A pesquisa identificou o uso de 87 onomatopeias nas HQ das 27 edições da revista Recrutinha. Conforme Tabela 1, é possível constatar dois momentos na produção das histórias em quadrinhos em questão, de 2008 a 2013, com uma baixa quantidade ou mesmo inexistência de onomatopeias nas edições analisadas. $\mathrm{O}$ índice do período foi de duas onomatopeias por edição, o que transforma as histórias em quadrinhos em produtos de comunicação social quase sinestésico ou pobre em sonoridade. Num segundo momento, de 2014 a 2017, as HQ Recrutinha ganham uma riqueza maior nas onomatopeias. O levantamento do segundo momento indica um índice de cinco onomatopeias por edição. Na Tabela 2, segue a apresentação das onomatopeias representadas no período de 2008 a 2013 e, na Tabela 3, segue a apresentação das onomatopeias do período entre 2014 e 2017.

Tabela 2 - Apresentação das onomatopeias das HQ Recrutinha (2008-2013)

\begin{tabular}{|l|l|l|l|}
\hline Ano & Ref & Onomatopeia & Representa a sonoridade de \\
\hline 2008 & \multicolumn{2}{|l|}{ Não há onomatopeias nas 4 edições publicadas no ano } \\
\hline \multirow{3}{*}{2009} & 1 & ZZZZ & (dormindo) \\
\cline { 2 - 4 } & 2 & VUP! VUP! VUP! & (movimento de rotação) \\
\cline { 2 - 4 } & 3 & $\begin{array}{l}\text { TRIIMMMM } \\
\text { GOSTAMOS!!! }\end{array}$ & $\begin{array}{l}\text { Campainha escolar } \\
\text { Grito de uníssono na sala }\end{array}$ \\
\hline \multirow{2}{*}{2010} & 1 & $1,2,3 \ldots$ & Tropas treinando \\
\cline { 2 - 4 } & \multirow{2}{*}{ Felicidade } \\
\hline
\end{tabular}




\section{VOZES $_{\text {\&IÁLOGO }}$}

Itajaí, v. 17, n. 02, jul./dez. 2018

\begin{tabular}{|c|c|c|c|}
\hline & & $\begin{array}{l}\text { VIVA!; ÔBA!!; } \hat{\mathrm{E}} \hat{\mathrm{E}} \hat{\mathrm{E}} ; \\
\text { AAHHH!!! }\end{array}$ & \\
\hline & 2 & $\begin{array}{l}1,2,3 \ldots \\
\text { POU; SOC } \\
\text { AH SIM! } \\
\text { HA! HA! HA! }\end{array}$ & $\begin{array}{l}\text { Tropas treinando } \\
\text { Luta } \\
\text { Entendimento } \\
\text { Risos }\end{array}$ \\
\hline & 3 & $\begin{array}{l}\text { OBBA!; VIVA!; QUE } \\
\text { LEGAL! }\end{array}$ & Felicidade \\
\hline 2011 & 1 & $\begin{array}{l}\text { SOLDADO? } \\
\text { Ah!; Legal!; Seremos } \\
\text { todos soldados! }\end{array}$ & $\begin{array}{l}\text { Dúvida } \\
\text { Comemoração }\end{array}$ \\
\hline 2012 & 1 & $\begin{array}{l}\text { COF! COF! COF! } \\
\text { TUMP! } \\
\text { ZUP }\end{array}$ & $\begin{array}{l}\text { Tosse } \\
\text { Coelho saindo da toca } \\
\text { Coelho entrando na toca }\end{array}$ \\
\hline & 2 & $\begin{array}{l}\text { Oba!; Queremos, sim!; } \\
\text { Adoramos! }\end{array}$ & Comemoração \\
\hline & 1 & - & - \\
\hline 2013 & 2 & $\begin{array}{l}\text { BRUMMM! } \\
\text { ROARRR! } \\
\text { Plec }\end{array}$ & $\begin{array}{l}\text { Estrondo } \\
\text { Grunhido dos monstros } \\
\text { Estalar de dedos }\end{array}$ \\
\hline & 3 & $\begin{array}{l}\text { AH!AH!AH!; HA! HA! } \\
\text { HA! }\end{array}$ & Alegria (risos) \\
\hline
\end{tabular}

Ref. Referência (é a ordenação das edições publicadas pela data de lançamento)

Fonte: o autor com base em (RECRUTINHA, 2008-2013).

A representação de onomatopeias do primeiro período, revelou que das 32 onomatopeias, 24 eram de sentidos diferentes como apresentado na Tabela 2.

Tabela 3 - Apresentação das onomatopeias das HQ Recrutinha (2014-2017)

\begin{tabular}{|c|c|c|c|}
\hline Ano & Ref & Onomatopeia & Representa a sonoridade de \\
\hline \multirow{9}{*}{2014} & & EINS TEIN & Campainha \\
\hline & & POW & Estouro \\
\hline & & WHAT? & Voar \\
\hline & 1 & ZOOOM; ZAAAP & Velocidade \\
\hline & & VUP & Rotação \\
\hline & & PUFF! & Surgir \\
\hline & & BOOM! & Explosão \\
\hline & 2 & $\begin{array}{l}\text { BOOMM } \\
\text { VENCEMOS! }\end{array}$ & $\begin{array}{l}\text { Explosão } \\
\text { Comemoração }\end{array}$ \\
\hline & 3 & - & - \\
\hline 2015 & 1 & $\begin{array}{l}\text { PLACT PLACT } \\
\text { POW; KA-POW; } \\
\text { UUI?! HUH?! } \\
\text { VIVA! } \\
\text { CLAP! CLAP! }\end{array}$ & $\begin{array}{l}\text { Marchando } \\
\text { BRIGA } \\
\text { Comemoração } \\
\text { Aplausos }\end{array}$ \\
\hline
\end{tabular}




\section{VOZES $_{\text {\&IÁLOCO }}^{\mid}$}

Itajaí, v. 17, n. 02, jul./dez. 2018

\begin{tabular}{|c|c|c|c|}
\hline & 2 & $\begin{array}{l}\text { EBBAAAAA!; } \\
\text { EEEEEUUUUUU! } \\
\text { TUNK!; TUFF } \\
\text { GOOOOLLLL! } \\
\text { CLIC! } \\
\text { HA! HA! HA! }\end{array}$ & $\begin{array}{l}\text { Comemoração } \\
\text { Barulho de robôs } \\
\text { Comemoração de jogo } \\
\text { Acender lâmpada } \\
\text { Risos }\end{array}$ \\
\hline & 3 & $\begin{array}{l}\text { SHUK! } \\
\text { TUC! TUC! } \\
\text { ZZZZZ } \\
\text { ZUUPP! } \\
\text { AHHHHH! } \\
\text { RISC! }\end{array}$ & $\begin{array}{l}\text { Armando armadilha } \\
\text { Passadas } \\
\text { Dormir } \\
\text { Movimento (cortando o ar) } \\
\text { Grito } \\
\text { Lápis 'riscando' o papel }\end{array}$ \\
\hline \multirow{3}{*}{2016} & 1 & $\begin{array}{lll}\text { GOOL; } & \text { Obaa!!! } & \\
\text { Um... dois... } & \text { três... } \\
\text { quatro... } & & \\
\text { Quatro... } & \text { três... } & \text { dois... } \\
\text { um... } & & \\
\text { PRIIIIII } & & \\
\text { CHUTE } & & \end{array}$ & $\begin{array}{l}\text { Comemoração } \\
\text { Tropas treinando } \\
\text { Tropas treinando } \\
\text { Apito } \\
\text { Chutar a bola }\end{array}$ \\
\hline & 2 & $\begin{array}{l}\text { ZAP! } \\
? \\
\text { ZZZZ } \\
\text { ZAAP! } \\
\text { RIIRIIIRRII! } \\
\text { BONG } \\
\text { RISC } \\
\text { ADEUS } \\
\end{array}$ & $\begin{array}{l}\text { Deslocamento temporal } \\
\text { Silêncio (Surpresa) } \\
\text { (dormindo) } \\
\text { Cortar de corda } \\
\text { Relinchar } \\
\text { Luta } \\
\text { Riscar da escrita no papel } \\
\text { Saudação }\end{array}$ \\
\hline & 3 & - & - \\
\hline \multirow[b]{2}{*}{2017} & 1 & $\begin{array}{l}\text { ZUP! } \\
\text { RASG }\end{array}$ & $\begin{array}{l}\text { Fechar de tampa } \\
\text { Rasgar }\end{array}$ \\
\hline & 2 & $\begin{array}{l}\text { AU! AU! AU! (3) } \\
\text { TUMP! } \\
\text { VRUMMM!!! } \\
\text { HU!HU!HU! } \\
\text { DING DONG! } \\
\text { SLOFT! } \\
\text { Tumc! } \\
\text { ZUP } \\
\text { AAAAAAAAA }\end{array}$ & $\begin{array}{l}\text { Latido } \\
\text { Salto } \\
\text { Caminhão } \\
\text { Dança da chuva } \\
\text { Campainha } \\
\text { Areia caindo } \\
\text { Fechar da tampa de caixa d' } \\
\text { água } \\
\text { Voo de mosquito } \\
\text { grito }\end{array}$ \\
\hline
\end{tabular}

Ref. Referência (é a ordenação das edições publicadas pela data de lançamento) Fonte: o autor com base em (RECRUTINHA, 20014-2017).

A diferença na presença de onomatopeias reflete dois momentos na produção do Recrutinha pelo Centro de Comunicação Social do Exército, órgão responsável pela produção da revista de histórias em quadrinhos Recrutinha. O autor Luiz Fernando trabalhou como freelancer até o ano de 2013, e como funcionário concursado daquele 


\section{VOZES $_{\text {\&DÁLORO }}$}

Itajaí, v. 17, n. 02, jul./dez. 2018

Centro a partir de 2014. Em entrevista, Luiz Fernando revela que o tempo entre o planejamento do roteiro, etapa de desenho, arte final e impressão que era de menos de uma semana aumentou para cerca de um mês, fato que ampliou qualitativamente o processo de criação das edições mais recentes. $\mathrm{O}$ autor do Recrutinha revela a importância das onomatopeias para as HQ do herói:

As onomatopeias são usadas para trazer "som" às cenas, o gibi do Recrutinha por ser cheios de ação, com Carros de Combate, saltos de paraquedas, diversas missões do Exército, enfim, têm bastante potencial para empregar os barulhos em cada cena. Os estudos de uso delas, são geralmente exclusivas do gibi, existem várias explosões na revistinha, o que ajuda na criação. Cada onomatopeia tem sua particularidade. Se eu aumento o tamanho ou força das letras, eu mostro a intensidade do barulho. Outra coisa muito comum é usar cores características com cada "som". Nas explosões sempre uso vermelha ou laranja e no caso de terem cenas com água jorrando, por exemplo, uso cores mais azuladas. Sempre busco cores correspondentes para dar mais ênfase aos efeitos. Deixando, assim, a leitura mais agradável (ROCHA, 2018)

As HQ Recrutinha foram analisadas qualitativamente conforme Figura 1 e 2 na qual a primeira é a representação de várias vinhetas onde o uso de onomatopeias poderia ser utilizado para enriquecer a narrativa.

Figura 1 - Histórias em Quadrinhos com ausência de onomatopeias.

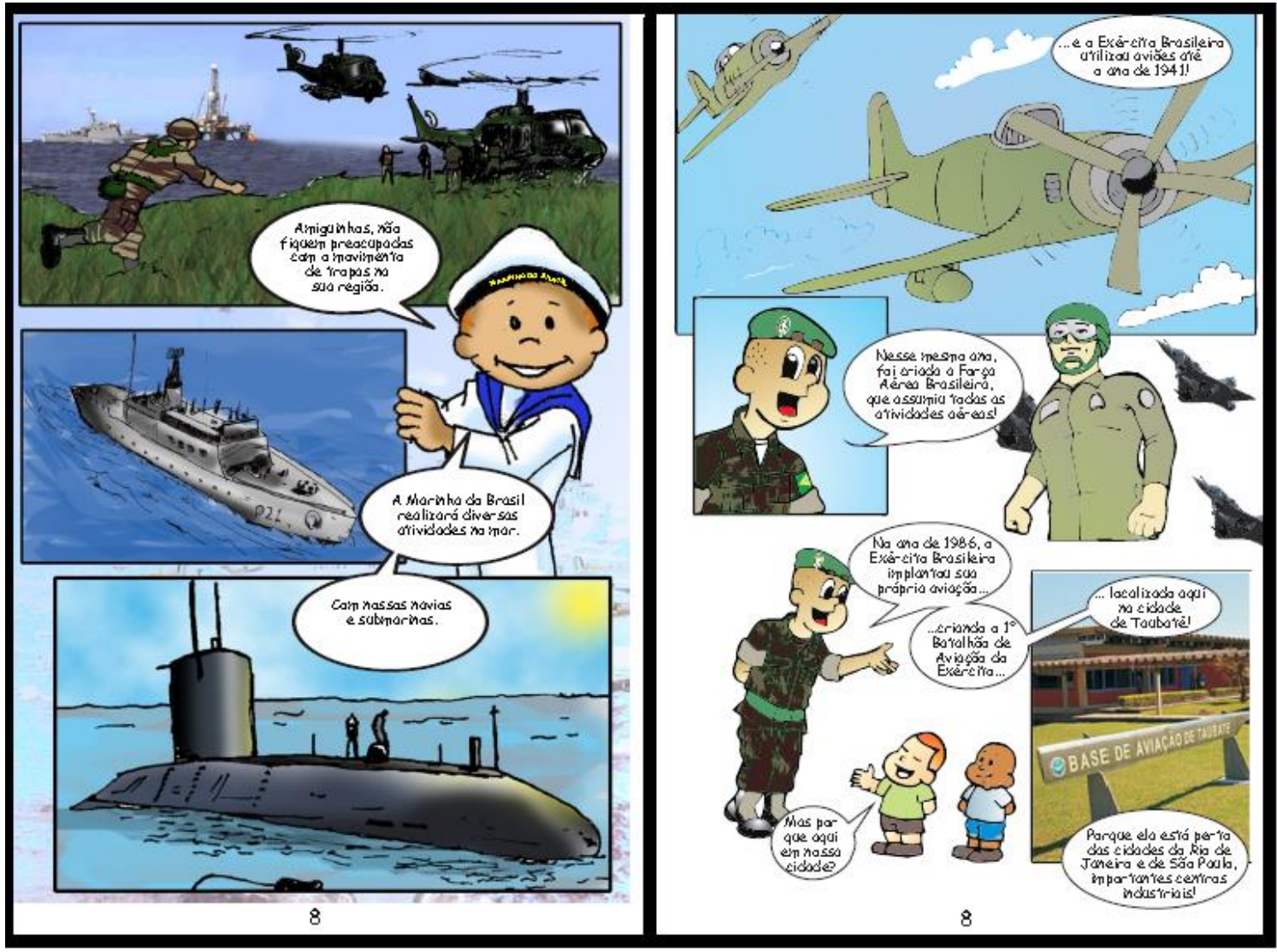




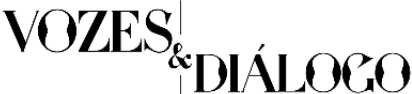

Itajaí, v. 17, n. 02, jul./dez. 2018

Fonte: Recrutinha (2008, p. 8; 2012, p.8)

Observa-se que na Figura 1, uma sequência de vinhetas à esquerda referente ao ano de 2008, na qual os helicópteros, navio, submarino e o próprio mar aparecem estáticos como pinturas por uma representação sem o dinamismo sonoro, que provoca uma inferência de falta de movimento na interpretação da narrativa. À direita, as vinhetas de 2012 apresentam a falta do ruído dos aviões, o próprio ruído do vento suprimido, novamente transmitindo a sensação de silêncio e estática.

Observa-se, na Figura 2, o grande número do uso de onomatopeias, ao todo cinco tipos em uma página, como Shuk! (som de armando dispositivo), Tuc! (barulho de passos do personagem), ZZZZ (som de pessoa dormindo), AAHHH (som de grito) e Zup! (barulho de deslocamento de ar - no caso da corda que corre em alta velocidade e desloca $\mathrm{o}$ ar ao seu redor) fornecem uma trilha sonora das ações na narrativa.

Figura 2 - Presença de onomatopeias na HQ Recrutinha.

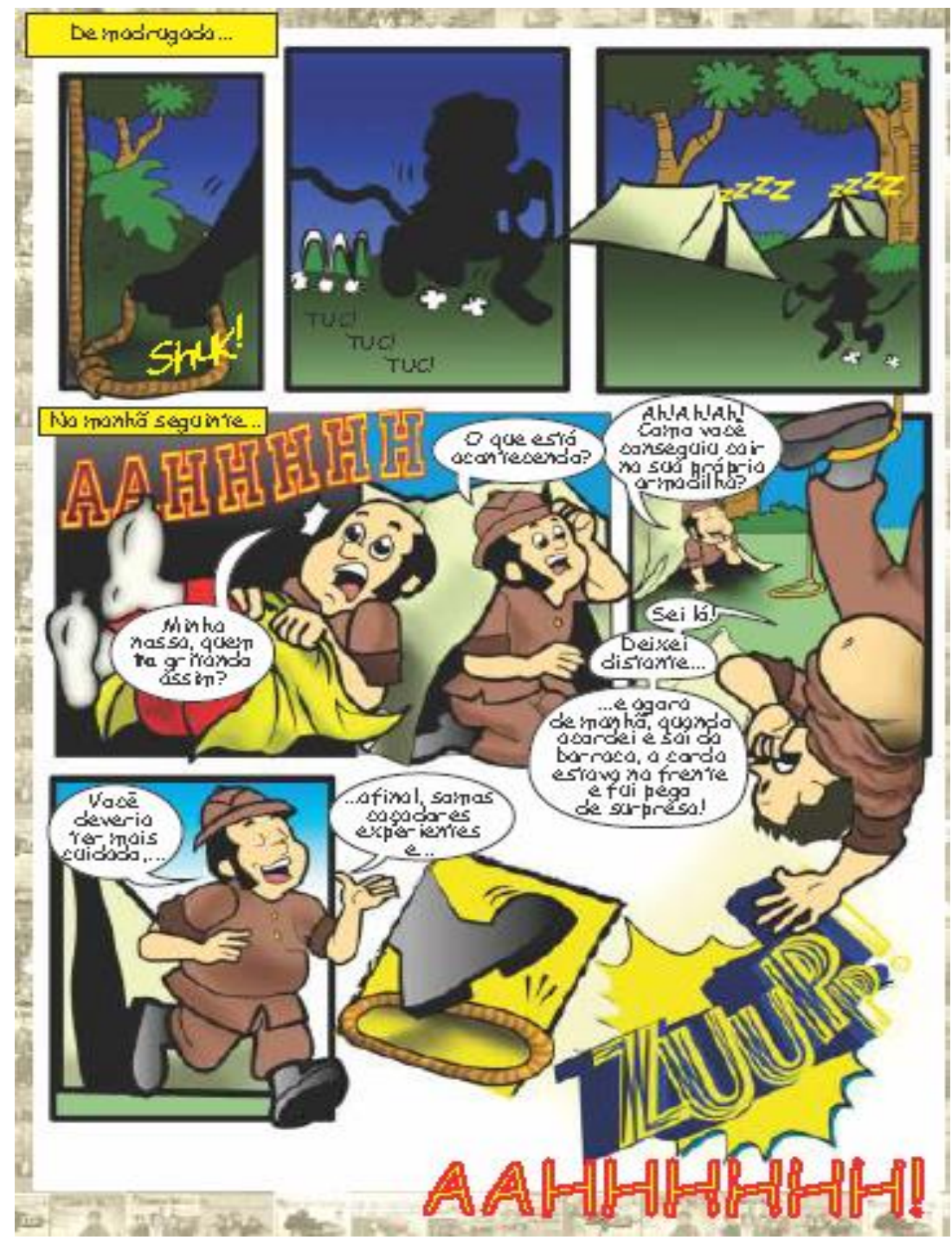




\section{VOZES $_{\text {\&IÁLOGO }}$}

Itajaí, v. 17, n. 02, jul./dez. 2018

Fonte: Recrutinha (2015, p. 4)

O recurso linguístico onomatopeia é fundamental para complementar a ideia, fornecendo sonoridade, ação e movimento, tornando emocionante a leitura da história em quadrinhos, no caso, as da revista Recrutinha. É também uma excelente oportunidade para melhorar a receptividade do produto de comunicação social para divulgar a instituição Exército Brasileiro junto à sociedade. Na Figura 3, o emprego combinado das onomatopeias de som (Puff), do som do movimento (Zooom) e do som da trajetória (Vup), numa única vinheta sintetiza o momento da viagem no tempo que o autor deseja transmitir ao leitor. Permite assim, a percepção do som, movimento e trajetória formando a narrativa sonora nas HQ pelo emprego combinado das onomatopeias.

Figura 3 - Combinação de onomatopeias

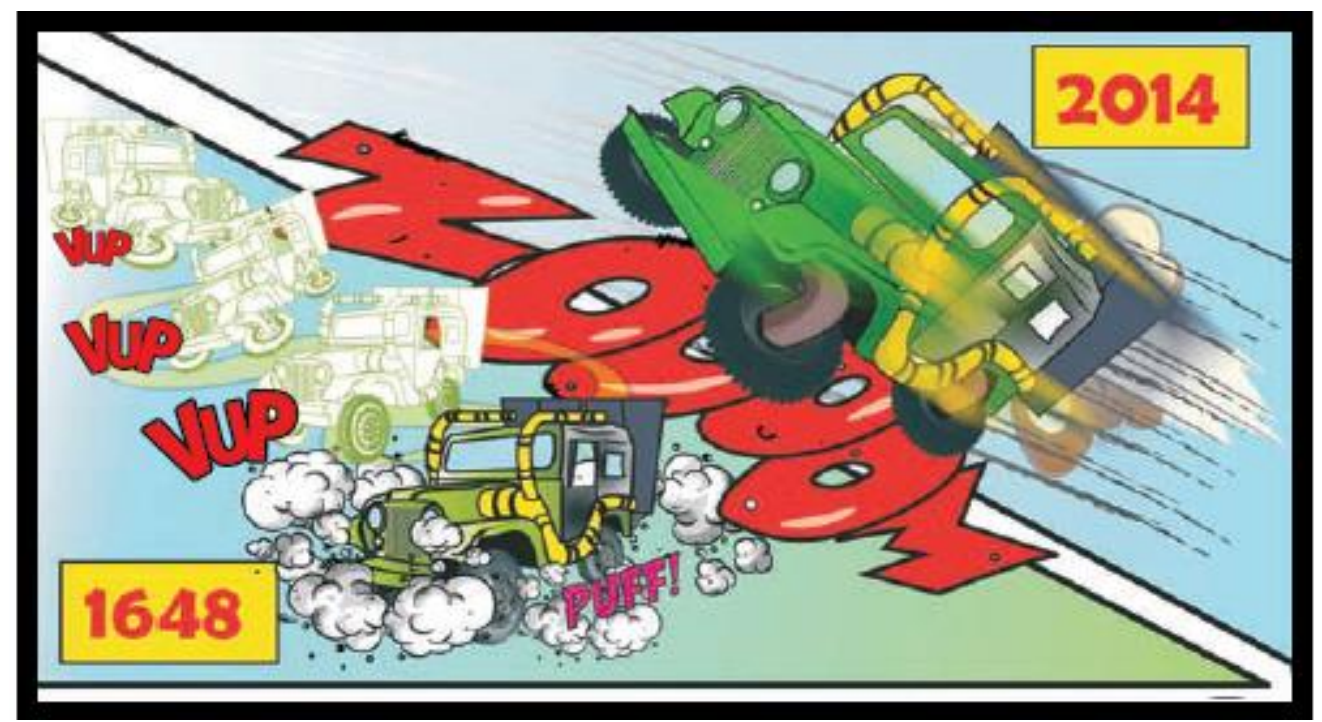

Fonte: Recrutinha (2014, p. 10)

A criatividade é uma das marcas na inserção das onomatopeias que, geralmente, imitam o som ou são a representação de palavras que definem o momento como chute, soco etc. Nas HQ Recrutinha, a criatividade representativa das onomatopeias fica em evidência na campainha da casa de um cientista que, ao soar, substitui o tradicional Ding Dong por Eins tein, uma criativa referência intertextual ao cientista Albert Einstein, conforme apresentado na Figura 4. 


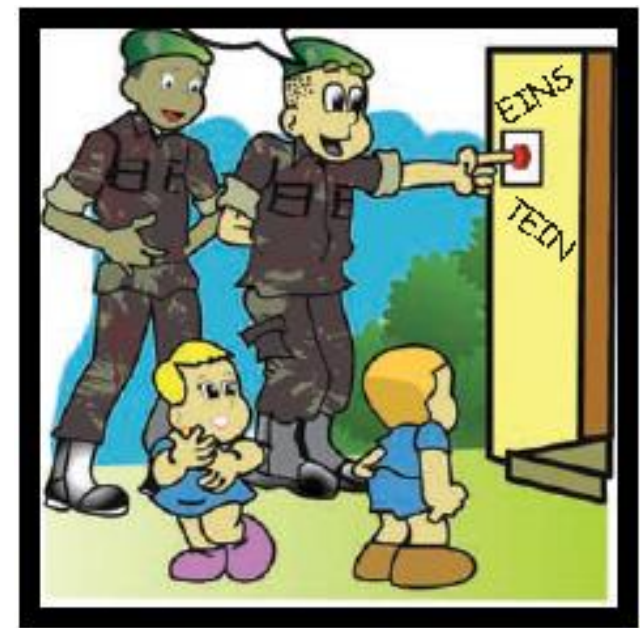

Fonte: Recrutinha (2014, p. 4)

\section{Considerações finais}

O recurso linguístico onomatopeia é fundamental para complementar a ideia, fornecendo sonoridade, ação e movimento, tornando emocionante a leitura da história em quadrinhos, no caso, as da revista Recrutinha. É importante destacar a melhoria das histórias em quadrinhos Recrutinha pelo aumento quantitativo e qualitativo do emprego de onomatopeias. Por fim, a preocupação com o emprego das onomatopeias é uma excelente oportunidade para melhorar a receptividade do conteúdo deste produto de comunicação social organizacional e para divulgar a instituição Exército Brasileiro junto à sociedade.

\section{Referências}

BARDIN, Laurence. Análise de conteúdo. São Paulo: Edições 70, 2011.

BARROS, Antonio; DUARTE, Jorge. (org.). Métodos e técnicas de pesquisa em comunicação. 2. ed. São Paulo: Atlas, 2017.

CIRNE, Moacy. A linguagem dos quadrinhos. 2. ed. Petrópolis: Vozes, 1971.

LUYTEN, Sonia Maria Bibe (org.). Histórias em quadrinhos: leitura crítica. São Paulo: Paulinas, 1984. 


\section{VOZES $_{\& \text { DIÁLORO }}^{\downarrow}$}

Itajaí, v. 17, n. 02, jul./dez. 2018

MEIRELES, Selma Martins. Quadrinhos e linguística: onomatopeias e interjeições e suas funções na narrativa em quadrinhos. In: VERGUEIRO, Waldomiro; SANTOS, Roberto Elísio dos (org.). A linguagem dos quadrinhos. São Paulo: Criativo, 2015.

RABAÇA, Carlos Alberto; BARBOSA, Gustavo Guimarães. Dicionário de Comunicação. 4 ed. Rio de Janeiro: Elsevier, 2001.

RAMOS, Paulo. A leitura dos quadrinhos. 2. ed. São Paulo: Contexto, 2016.

RECRUTINHA. Revista Recrutinha (2008-2017). Disponível em: http://www.eb.mil.br/web/noticias-e-multimidia/recrutinha/revista-do-recrutinha $>$. Acesso em: 3 set. 2017. . Operação Atlântico. Distrito Federal: Exército Brasileiro, 2008.

___-_-_. 25 anos Aviação Exército Brasileiro. Distrito Federal: Exército Brasileiro, 2012. Uma viagem no tempo. Distrito Federal, Exército Brasileiro, 2014. . Almanaque do Recrutinha. Distrito Federal: Exército Brasileiro, 2015.

ROCHA, Luiz Fernando Vieira Moreira. Entrevista concedida ao pesquisador. 09 mar. 2018 